\title{
Étienne Dolet, Carmina (1538)
}

\section{Dario Cecchetti}

\section{(2) OpenEdition \\ Journals}

\section{Edizione digitale}

URL: http://journals.openedition.org/studifrancesi/7168

DOI: 10.4000/studifrancesi.7168

ISSN: 2421-5856

\section{Editore}

Rosenberg \& Sellier

\section{Edizione cartacea}

Data di pubblicazione: 1 avril 2010

Paginazione: 132-133

ISSN: 0039-2944

\section{Notizia bibliografica digitale}

Dario Cecchetti, «Étienne Dolet, Carmina (1538)», Studi Francesi [Online], 160 (LIV | I) | 2010, online dal 30 novembre 2015, consultato il 10 janvier 2021. URL: http://journals.openedition.org/studifrancesi/ 7168 ; DOI: https://doi.org/10.4000/studifrancesi.7168

Questo documento è stato generato automaticamente il 10 janvier 2021.

\section{(c) $($ ) $(9)$}

Studi Francesi è distribuita con Licenza Creative Commons Attribuzione - Non commerciale - Non opere derivate 4.0 Internazionale. 


\title{
Étienne Dolet, Carmina (1538)
}

\author{
Dario Cecchetti
}

\section{NOTIZIA}

ÉTIENNE DOLET, Carmina (1538), édition traduite et annotée, précédée d'une introduction sur sa poétique par Catherine LANGLOIS-PÉZERET, Genève, Droz, 2009 ( «Travaux d'Humanisme et Renaissance», n. CDLV), pp. 671.

1 Viene offerta la prima edizione critica moderna dei Carminum libri quatuor di Étienne Dolet (1538), accompagnata da una traduzione e da un'accurata annotazione. Il libro I di questi Carmina «obbedisce a una doppia prospettiva, programmatica, in quanto parecchie pièces spiegano le scelte poetiche e simboliche di Dolet dato che la tematica dell'amore e dell'amicizia rinvia alla giovinezza del poeta». Accanto alle composizioni d'interesse biografico-concernenti appunto l'amore e l'amicizia-abbiamo composizioni d'interesse teorico, ad esempio quelle in cui Dolet sottolinea la superiorità della poesia sull'oratoria o delle lettere sulle armi, o spiega l'importanza di un genere minore quale l'epigramma oppure illustra le sue preferenze per il verso giambico. Alcune poesie hanno un carattere morale (considerazioni sulla vita di corte, o divagazioni sulla virtù), altre un carattere satirico, come il breve ciclo I, 44-I, $50 \mathrm{su}$ prostitute e viziosi. Nel libro II comincia l'evocazione della vita a Lione (1534-1537) e del sodalitium Lugdunense, cui vengono indirizzati numerosi epigrammi: si tratta di Rabelais, Guillaume Scève, Marot, Nicolas Bourbon, Jean Visagier, Guillaume du Choul, il segretario di Dolet, Jacques Billet. Nel libro III si compie un passo indietro nel tempo, in quanto Dolet vi raggruppa epigrammi che si riferiscono all'epoca tolosana (1532-1534): i primi ventisei sono una requisitoria contro l'ambiente di Tolosa e i tolosani; alcune composizioni, poi, si situano nel quadro dei Jeux Floraux. Il libro IV è quasi intieramente consacrato a epigrammi-epitafi: concernono autori ciceroniani (Longueil, Neufville, Alberto Pio da Carpi); evocano grandi figure del tempo (Erasmo, Lefèvre d'Étaples, il delfino di Francia, Madeleine de Valois, il re di Navarra, Anna 
Bolena e Tommaso Moro); celebrano personaggi tolosani più o meno celebri (Jean de Pins, Jacques de Minut).

2 Interrogandosi sui motivi che spingono a editare i Carmina di Dolet, C. Langlois-Pézeret così riassume la portata e il significato della raccolta: «pur iscrivendosi nella filiazione alessandrina come molti neo-latini, Dolet cerca temerariamente di praticare delle forme nuove (racconti ridotti ad epigramma, xenia, ecc.) dalla varietà eccezionale (soggetti, registri, metrica); inoltre è l'audace promotore di un'estetica laica, affrancata dalle costrizioni della religione cristiana, e talvolta un po' ribelle» (p. 37). Precede l'edizione un ampio studio (in cui confluisce una thèse de doctorat) volto a ricostruire poetica, estetica ed ideologia di Dolet. La poetica è illustrata nel primo capitolo («Théorie et pratique poétique», pp. 41-90) ove si analizza la riflessione doletiana su ingenium e ars e si confronta il discorso teorico in rapporto sia alle artes classiche sia a quelle rinascimentali. Al ruolo del poeta e alla sua superiorità è consacrato il secondo capitolo («Splendeurs, misères et devoirs du poète», pp. 91-116). Viene quindi affrontato in un terzo capitolo il problema del ciceronianesimo («L'imitation cicéronienne dans le recueil des "Carmina"», pp. 117-160). Un quarto capitolo («L'épigramme dans les "Carmina”: une pratique atypique», pp. 161-197) studia il trattamento doletiano dell'epigramma, nella fedeltà alla tradizione classica (imitazione di Catullo e Marziale) e nella rottura con questa tradizione, in una ricerca di originalità anche sul piano della sperimentazione metrica. Il quinto capitolo infine («Les choix moraux et idéologiques de Dolet», pp. 199-244) enuclea le scelte ideologiche (viene evocato il Dolet libre penseur) a partire sempre da un'analisi dei Carmina di cui viene ribadita la straordinaria varietà formale e concettuale. Ricchissima la bibliografia. 